\title{
Molecular Optical Imaging: Applications Leading to the Development of Present Day Therapeutics
}

\author{
Khalid Shah* ${ }^{\dagger}$ and Ralph Weissleder* \\ * Center for Molecular Imaging Research and ${ }^{\dagger}$ Department of Neurology, Massachusetts General Hospital, Harvard Medical \\ School, Boston, Massachusetts 02114
}

\begin{abstract}
Summary: A number of advances in the molecular imaging field have led to the sensing of specific molecular targets and pathways in living animals. In the optical imaging field, these include the designing of biocompatible near-infrared fluorochromes, development of targeted and activatable "smart" imaging probes, and engineering of activatable fluorescent and bioluminescent proteins. The current advances in molecular optical imaging will help in early disease diagnoses, functioning of a number of pathways and finally help speed drug
\end{abstract}

discovery. In this review, we will describe the near infrared fluorescent and bioluminescence imaging modalities and how these techniques have been employed in current research. Furthermore, we will also shed some light on the use of these imaging modalities in neurotherapeutics, for example imaging different parameters of vector-mediated gene expression in glioma tumors and stem cell tracking in vivo. Key Words: Optical imaging, near-infrared fluorochromes, fluoresce, bioluminescence, viral proteases, gene expression.

\section{INTRODUCTION}

Recent advances in molecular and cell biology techniques have helped us to understand a number of human disorders that have ultimately led to the development of novel therapeutics and a changed clinical approach at patient level. One of the most critical issues for ensuring success of understanding diseases and developing new therapies is the development of noninvasive high-resolution in vivo imaging technologies. The in vivo monitoring of specific molecular and cellular processes (e.g., gene expression, multiple simultaneous molecular events, progression or regression of cancer, and drug and gene therapy) are the major goals of this evolving technology. In recent years, many advances have been made in high-resolution in vivo imaging methods, including: radionuclide imaging, such as positron emission tomography (PET) and single-photon emission tomography (SPECT), magnetic resonance (MR) imaging, and spectroscopy. Optical imaging techniques have used different physical parameters of light interaction with tissue and a number of different optical imaging approaches have been described. These techniques rely on fluorescence,

Address correspondence and reprint requests to Khalid Shah, Ph.D., CMIR, Massachusetts General Hospital, 13th Street, Building 149, Charlestown, MA 02129. E-mail: kshah@helix.mgh.harvard.edu. absorption, reflectance, or bioluminescence as a source of contrast (Table 1). The recently used optical imaging techniques that are gaining popularity include NIRF (near-infrared fluorescence) reflectance imaging and bioluminescence imaging. These optical techniques have the potential for molecular specificity.

\section{NEAR-INFRARED FLUORESCENCE REFLECTANCE IMAGING}

Light in the visible-wavelength range is routinely used for conventional and intravital microscopy. ${ }^{1}$ Because hemoglobin (the principal absorber of visible light), water and lipids (the principal absorbers of infrared light) have their lowest absorption coefficient in the near-infrared (NIR) region of approximately 650-900 nm (FIG. 1A), the use of NIR light is ideal for imaging deeper tissues. Imaging in the NIR spectrum $(700-900 \mathrm{~nm})$ maximizes tissue penetrance in addition to minimizing the autofluorescence from nontarget tissue. NIR fluorescence imaging relies on light with a defined bandwidth as a source of photons that encounter a fluorescent molecule (optical contrast agent). This fluorescent molecule then emits a signal with different spectral characteristics that can be resolved with an emission filter and captured with an ultrasensitive charge-coupled device (CCD) camera. In- 
TABLE 1. Optical in Vivo Imaging Systems

\begin{tabular}{|c|c|c|c|c|c|}
\hline Imaging Methods & $\begin{array}{l}\text { Maximum } \\
\text { Depth }\end{array}$ & Target & Time & $\begin{array}{l}\text { Primary Small } \\
\text { Animal Use }\end{array}$ & $\begin{array}{l}\text { Clinical } \\
\text { Potential }\end{array}$ \\
\hline Confocal microscopy & $300 \mu \mathrm{m}$ & $\begin{array}{l}\text { Physiological, } \\
\text { molecular }\end{array}$ & Sec/Min & $\begin{array}{l}\text { Gene expression, reporter } \\
\text { enzyme targeting, high } \\
\text { sensitivity and use in } \\
\text { quantitative translational } \\
\text { research }\end{array}$ & Experimental \\
\hline Two-photon microscopy & $800 \mu \mathrm{m}$ & $\begin{array}{l}\text { Physiological, } \\
\text { molecular }\end{array}$ & Sec/Min & $\begin{array}{l}\text { Gene expression imaging } \\
\text { multiple probes } \\
\text { simultaneously }\end{array}$ & Experimental \\
\hline $\begin{array}{l}\text { Fluorescence reflectance } \\
\text { imaging }\end{array}$ & $5-7 \mathrm{~mm}$ & $\begin{array}{l}\text { Physiological, } \\
\text { molecular }\end{array}$ & $\mathrm{Sec} / \mathrm{Min}$ & $\begin{array}{l}\text { Gene expression activat- } \\
\text { able, detects fluoro- } \\
\text { chromes in live and } \\
\text { dead cells }\end{array}$ & Yes \\
\hline $\begin{array}{l}\text { Diffuse optical } \\
\text { tomography }\end{array}$ & $15-20 \mathrm{~mm}$ & $\begin{array}{l}\text { Physiological, } \\
\text { molecular }\end{array}$ & $\mathrm{Sec}$ & & Yes \\
\hline $\begin{array}{l}\text { Fluorescence molecular } \\
\text { tomography }\end{array}$ & $0-15 \mathrm{~cm}$ & $\begin{array}{l}\text { Physiological, } \\
\text { molecular }\end{array}$ & $\mathrm{Sec}$ & $\begin{array}{l}\text { Quantitative imaging of } \\
\text { targeted fluorochrome } \\
\text { reporters in deep tissues }\end{array}$ & Yes \\
\hline Bioluminescence imaging & $2-3 \mathrm{~cm}$ & Molecular & Min & $\begin{array}{l}\text { Gene expression, cell } \\
\text { tracking, quick and easy }\end{array}$ & Experimental \\
\hline
\end{tabular}

terpretation of NIR data and images generally requires advanced data processing techniques to account for the diffuse nature of photon propagation in tissue.

The recent advances in NIRF imaging have been accelerated by the development of NIR fluorochromes coupled to quenching peptides that are activated by specific proteases at the target site. ${ }^{2}$ The NIRF probes typically consist of a delivery vehicle linked to the near infrared fluorochromes via the enzyme specific peptide substrates (FIG. 1B). The delivery vehicles are long-circulating, high-molecular weight synthetic-protected graft copolymers that have already been tested in clinical trials. ${ }^{3}$ The underpinning hypothesis of this approach is that most disease processes have a molecular basis that can be exploited to detect disease earlier or to monitor novel therapies by imaging molecular biomarkers. Studies with NIRF probes, both in culture and in vivo, have shown that the nonactivated probes have a very low background fluorescence and that protease activation of probes can increase the fluorescence over several hundredfold ${ }^{4}$ with probes detectable in the nanomolar range and with no apparent toxicity. ${ }^{5}$ In the past few years, NIRF imaging aided by activatable NIRF probes has been used for example in detecting tumors, apoptosis, and other molecular events in experimental models.

\section{DETECTION OF TUMORS AND EFFICACY OF PROTEASE INHIBITORS AND THERAPEUTIC PROTEINS}

A number of tumors have been shown to have elevated levels of proteolytic enzymes at an early stage. The pres- ence of these enzymes represents an attractive target for tumor imaging and designing therapeutic strategies. ${ }^{6}$ Using this as a basis, autoquenched NIRF probes that become active after protease activation have been used in imaging tumors that have upregulated levels of certain proteases, like cathepsins. ${ }^{7}$ Cathepsin B and cathepsin $\mathrm{H}$ protease activities have also been used to detect submillimeter sized tumors using NIR fluorescent probes. ${ }^{7}$ In addition, cathepsin D-positive tumors ${ }^{8}$ have also been imaged in mouse models (FIG. 2).

Similar to cathepsins, matrix metalloproteinases (MMPs) are overexpressed in a number of tumors ${ }^{9,10}$ and in inflamed tissues. ${ }^{11}$ The level of their expression has been shown to be directly related to the tumor stage ${ }^{12}$ and metastasis. ${ }^{13}$ A number of different MMP inhibitors (e.g., AG 3340), which act as cytostatic and anti-angiogenic agents and some of which are in clinical trials have been developed. ${ }^{14,15}$ One major hurdle in assessing the efficacy of such drugs has been the inability to detect or image antiproteinase activity directly and noninvasively in vivo. Recent developments allow NIRF-MMP substrates to be used as activatable NIRF reporter probes to monitor MMP activity in intact tumors. ${ }^{16}$ These probes have the advantage of directly imaging MMP activity within hours after treatment with potent MMP inhibitors.

During glioma progression, urokinase plasminogen activator receptor (UPAR) and cathepsin B are overexpressed, particularly at the leading edge of the tumor. ${ }^{17}$ In an effort to inhibit the activity of UPAR, an adenoviral vector carrying antisense UPAR and antisense cathepsin $\mathrm{B}$ was injected into the established gliomas. This resulted in a simultaneous down-regulation of UPAR and cathep- 


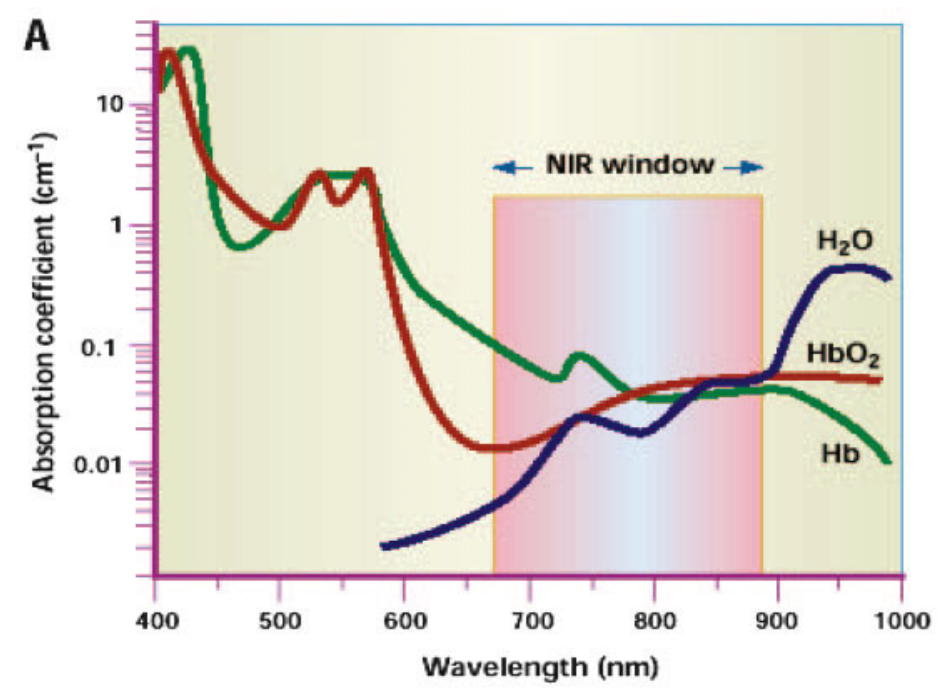

\section{B}

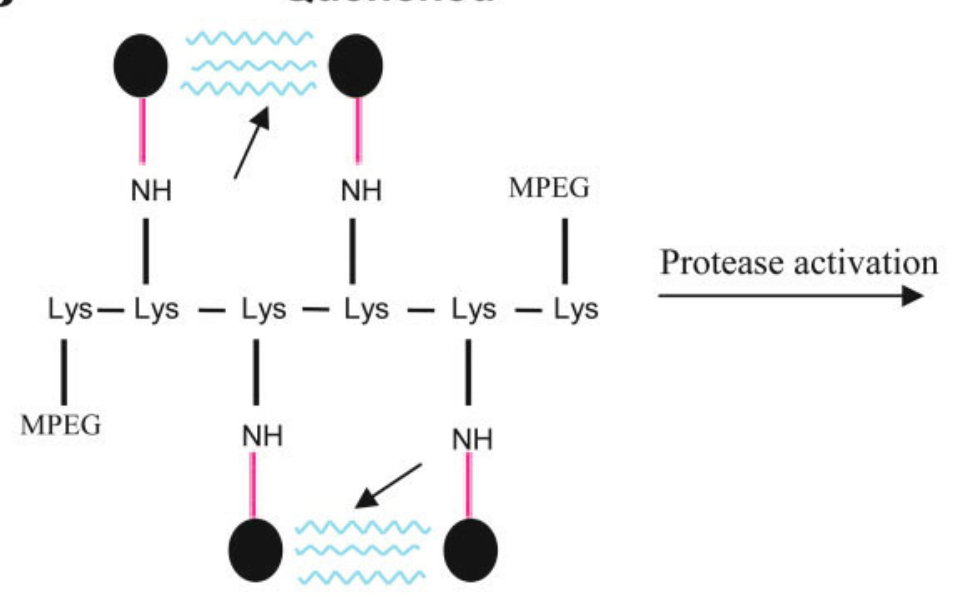

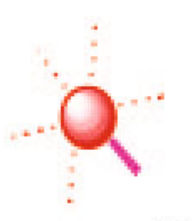

Activated

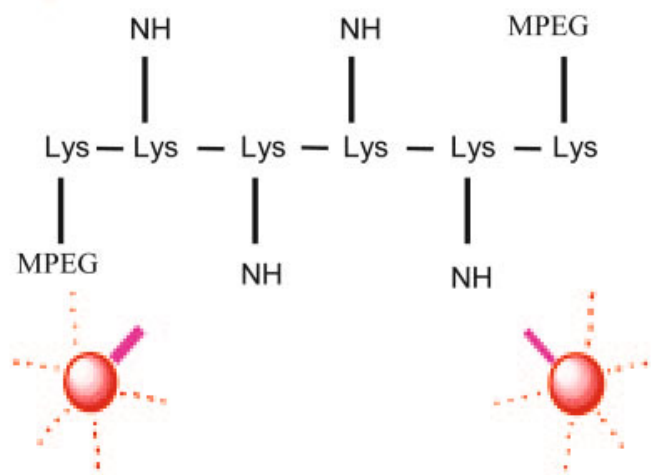

FIG. 1. A: Interaction of light with tissue. The absorption coefficient of light in tissue is dependent on wavelength and results from absorbers such as hemoglobins, lipids and water. Given the decreased absorption of light in the NIR region compared with visible light $(\sim 400-650 \mathrm{~nm})$ and infrared light $(>900 \mathrm{~nm})$, tissue penetration of NIR photons may be up to $10-15 \mathrm{~cm}$. B: Chemical structure of repeating graft copolymer segment indicating quenched and the activated state after the cleavage at the enzyme recognition sites indicated by arrows.

$\sin \mathrm{B}$ and a marked reduction in tumor growth and invasiveness. ${ }^{18} \mathrm{~A}$ cathepsin-B NIRF probe indicated low/ undetectable levels of fluorescence after injection of the engineered $\mathrm{uPAR} /$ cathepsin $\mathrm{B}$ adenoviral vector into preestablished tumors as compared to the controls. The down-regulation of cathepsin B and uPAR thus plays a significant role in inhibiting tumor growth, invasion, and angiogenesis and NIRF imaging offers a potential to detect the regulation of proteases like cathepsin $\mathrm{B}$ in gliomas in vivo.

\section{IMAGING APOPTOSIS WITH NIRF PROBES}

A deficiency or an excess of programmed cell death (apoptosis) is an integral component of autoimmune disorders, organ and bone marrow transplant rejection, and cancer. The transformation of a normal cell to an apoptotic cell is typically characterized by loss of cell volume, plasma membrane blebbing, nuclear chromatin condensation and aggregation, and endonucleocytic degradation of DNA into nucleosomal fragments. ${ }^{19}$ These 


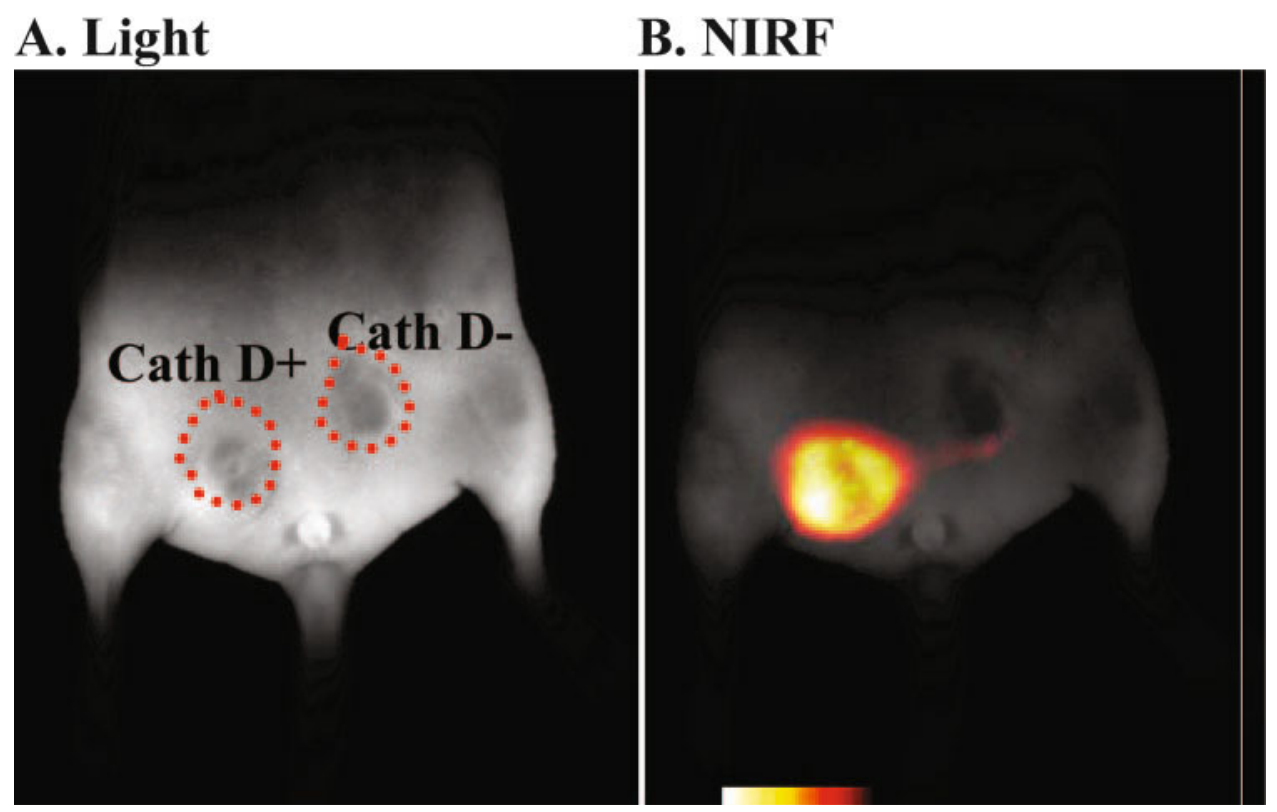

FIG. 2. In vivo NIRF imaging of upregulated proteases. Representative optical images of the lower abdomen of a nude mouse implanted with cathepsin D-positive and negative rat embryo (3Y1) tumors. A: White light image $24 \mathrm{~h}$ after intravenous injection of the cathepsin D-specific NIRF probe. B: Identical imaging set-up as in A, except that NIRF fluorescence is shown at $700 \mathrm{~nm}$. Note that the cathepsin D-positive tumor emits fluorescence, whereas the negative tumor has a significantly lower signal. Adapted with permission from Tung et al. In vivo imaging of proteolytic enzyme activity using a novel molecular reporter. Cancer Res 60:4953-4958. Copyright (C) 2000, American Association of Cancer Research. All rights reserved. ${ }^{8}$

cell changes occur following sequential activation of initiator and effector caspases (cysteinyl aspartate-specific proteinase). ${ }^{20-22}$ Caspase-1, also known as interleukin $1 \beta$-converting enzyme (ICE), is considered an initiator caspase. ${ }^{23}$ We have developed an NIRF probe selective for caspase-1 (ICE). Apoptosis, induced either with staurosporine, ganciclovir, ionizing radiation or by infection of cells with herpes simplex virus amplicon vector (HSV-ICE-lacZ) expressing a catalytically active caspase-1-lacZ fusion protein, was specifically detected in culture with ICE-NIRF probe. In vivo experiments in mice bearing gliomas and injected with the HSV-ICE vector showed a specific activation of ICE near-infrared probe. ${ }^{24}$ Thus, ICE-NIRF probe can be used in monitoring endogenous and vector-expressed caspase-1 activity in cells and should prove useful in monitoring endogenous and vector-expressed caspase- 1 activity, and potentially apoptosis in cell culture and in vivo.

One of the earliest indications of apoptosis is the translocation of the membrane phospholipid phosphatidylserine (PS) from the inner to the outer leaflet of the plasma membrane. ${ }^{25}$ Once exposed to the extracellular environment, binding sites on PS become available for Annexin $\mathrm{V}$, a $\mathrm{Ca}^{2+}$-dependent, phospholipid binding protein with a high affinity for PS. The translocation of PS precedes other apoptotic processes such as loss of plasma membrane integrity, DNA fragmentation, and chromatin condensation. Based on this, we have developed a NIRF annexin $\mathrm{V}$ probe to be used for optical sensing of tumor environments. To demonstrate the probe specificity, nude mice each bearing a cyclophosphamide (CPA) chemosensitive Lewis lung carcinoma (LLC) and a chemoresistant LLC (CR-LLC) were tested. ${ }^{26}$ After injection with active annexin V, the LLC of CPA-treated mice had significant elevations of the tumor-annexinV ratio (TAR; tumor NIRF/background NIRF), but only a moderate increase was obtained for the CR-LLC indicating that active $\mathrm{Cy}$-annexin $\mathrm{V}$ and surface reflectance fluorescence imaging provide a nonradioactive, semiquantitative method of determining chemosensitivity in LLC xenografts. The method maybe used to image pharmacologic responses in other animal models and, potentially, may permit the clinical imaging of apoptosis with noninvasive or minimally invasive instrumentation.

\section{IMAGING VIRAL PROTEASES}

The ability to image gene expression in vivo is critical to assess the efficacy of novel targeted viral vectors and to quantitate their therapeutic effects. To directly image transgenes, however, it is essential to develop protease/ substrate systems, which are not ubiquitously expressed in mammalian systems and viral proteases offer a possibility to design such systems. We have developed a NIRF probe for HIV (Human immunodeficiency virus)-1 protease (PR) for imaging of gene delivery to tumors in vivo and shown specific fluorescence activation of this NIRF probe in human Gli36 gliomas injected with HSV-1 amplicon vector expressing HIV-1PR. ${ }^{27}$. This study demonstrates that viral proteases delivered via vi- 
ral vectors can be imaged in live animals and thus serve as a transgene marker in tumor therapy as well as in testing the efficacy of HIV-1 protease inhibitors such as indinavir and ritonavir in vivo.

In a recent study we have coupled the regulation of a therapeutic protein, S-TRAIL [secreted tumor necrosis factor (TNF)-related apoptosis-inducing ligand $]^{28}$ with the activation of HSV-1 specific NIRF probe using the HSV-1 specific protease. As TRAIL acts by binding to its cognate receptors only on the cell surface, ${ }^{29,30}$ we have engineered an endoplasmic-reticulum (ER)-targeted-TRAIL that is retained in the ER until selectively released by the HSV-1 viral protease. We have shown that ER retention sequences direct the ER-S-TRAIL fusion protein into the ER and significantly blocks TRAILmediated apoptosis in glioma cells. Furthermore, this fusion protein can be released from the ER and secreted from cells expressing ER-targeted HSV-1 protease with subsequent induction of apoptosis in glioma cells. The same HSV-1 protease can be used to monitor gene delivery in vivo by systemic administration of HSV-1 protease specific NIRF probe activated by the protease (FIG. 3 , A-D). ${ }^{31}$ This study serves as a template for design of recombinant proteins to enhance and control apoptosis of tumor cells via specific viral-proteases, and for use of viral-proteases as in vivo reporters for cancer therapy.

NIRF imaging has also been used to elucidate other biological processes; for example, NIRF probes have been recently developed to better understand the role of factor XIII subunit A, FXIIIa in thrombosis and other biological processes to aid in the clinical detection of acute thrombi. Activated factor XIII (FXIIIa) mediates fibrinolytic resistance and is a hallmark of newly formed thrombi. ${ }^{32}$ A FXIIIa-sensitive near-infrared fluorescence imaging agent was engineered by conjugating a nearinfrared fluorochrome to a peptide ligand derived from the amino terminus of $\alpha 2$-antiplasmin. ${ }^{33}$ In vivo murine experiments with FXIIIa-sensitive near-infrared probe demonstrated significant signal enhancement in acute intravascular thrombi and minimal FXIIIa-sensitive nearinfrared probe enhancement in older aged thrombi, consistent with an expected decline of FXIIIa activity over time. This agent should thus permit assessment of FXIIIa activity in a broad range of biological processes and could aid in the clinical diagnosis of acute thrombi.

\section{BIOLUMINESCENCE IMAGING}

Bioluminescence imaging (BLI) has emerged as a useful and complementary experimental imaging technique for small animals. BLI exploits the emission of visible photons at specific wavelengths based on energy-dependent reactions catalyzed by luciferases. Luciferases comprise a family of photoproteins that emit detectable photons in the presence of oxygen and ATP during metabolism of substrates such as luciferin into oxyluciferin. Luciferase systems include, among others, the bacterial lux genes of terrestrial Photorhabdus luminescens and marine Vibrio harveyi bacteria, as well as eukaryotic luciferase luc and ruc genes from firefly species (Photinus) and the sea panzy (Renilla reniformis), respectively. The light from these enzyme reactions typically has very broad emission spectra that frequently extend beyond $600 \mathrm{~nm}$, with the red components of the emission spectra being the most useful for imaging by virtue of easy transmission through tissues. The light output per cell can be determined in culture as a priori assessment of the sensitivity of detecting a signal in a given animal model, although there is a marked reduction of signal in vivo. ${ }^{34}$ Typical doses of luciferin are in large excess $(120 \mathrm{mg} / \mathrm{kg}$ i.p.) and are injected immediately before data acquisition. Image acquisition times are on the order of minutes, depending on expression levels, depth and photon flux, and the light generated is detected and quantified using highly sensitive cooled CCD cameras. ${ }^{35,36}$

The predictions based on diffusion models and in vivo studies suggest that BLI can provide a sensitive and rapid assay for the study of oncogenesis and disease progression in living animal models. Furthermore, BLI in experimental animals complements other developments in the molecular imaging, field allowing real-time information about complex pathophysiological processes in living organisms. This will lead to a better understanding of the underlying biology and thus result in improved disease prevention and treatment. Luciferases have been used for real-time, low-light imaging of gene expression in cell cultures, individual cells, whole organisms, and transgenic organisms. Sensitive imaging systems have been built to detect and quantitate small numbers of cells or organisms expressing luciferase as a transgenes. ${ }^{37-39}$ BLI has been used to monitor tumor cell growth and regression $^{40,41}$ to visualize the kinetics of tumor cell clearance by chemotherapeutics ${ }^{42}$ and to track gene expression. $^{43}$

\section{SERIAL IMAGING OF TUMOR RESPONSE TO THERAPY IN VIVO}

Luciferase imaging has revealed gene transfer to tumors followed by a decrease in transgene expression with tumor cell death over time. A recombinant adenovirus coexpressing cytosine deaminase (CD) and firefly luciferase (Fluc) injected directly into the gliomas in mice showed significant expression of luciferase. ${ }^{44}$ Further treatment of animals with 5-fluorocytosine leads to a decrease in this imaging signal, presumably because of cell death. In parallel, diffusion-weighted MR imaging was used as a surrogate marker of tumor cell death. This multimodality approach thus provides noninvasive assessment of both the extent of gene delivery and the 
A
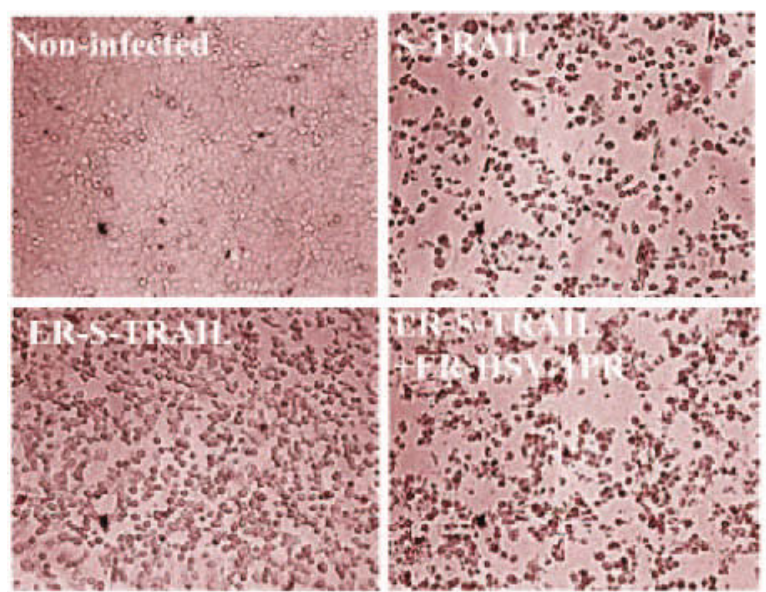

B
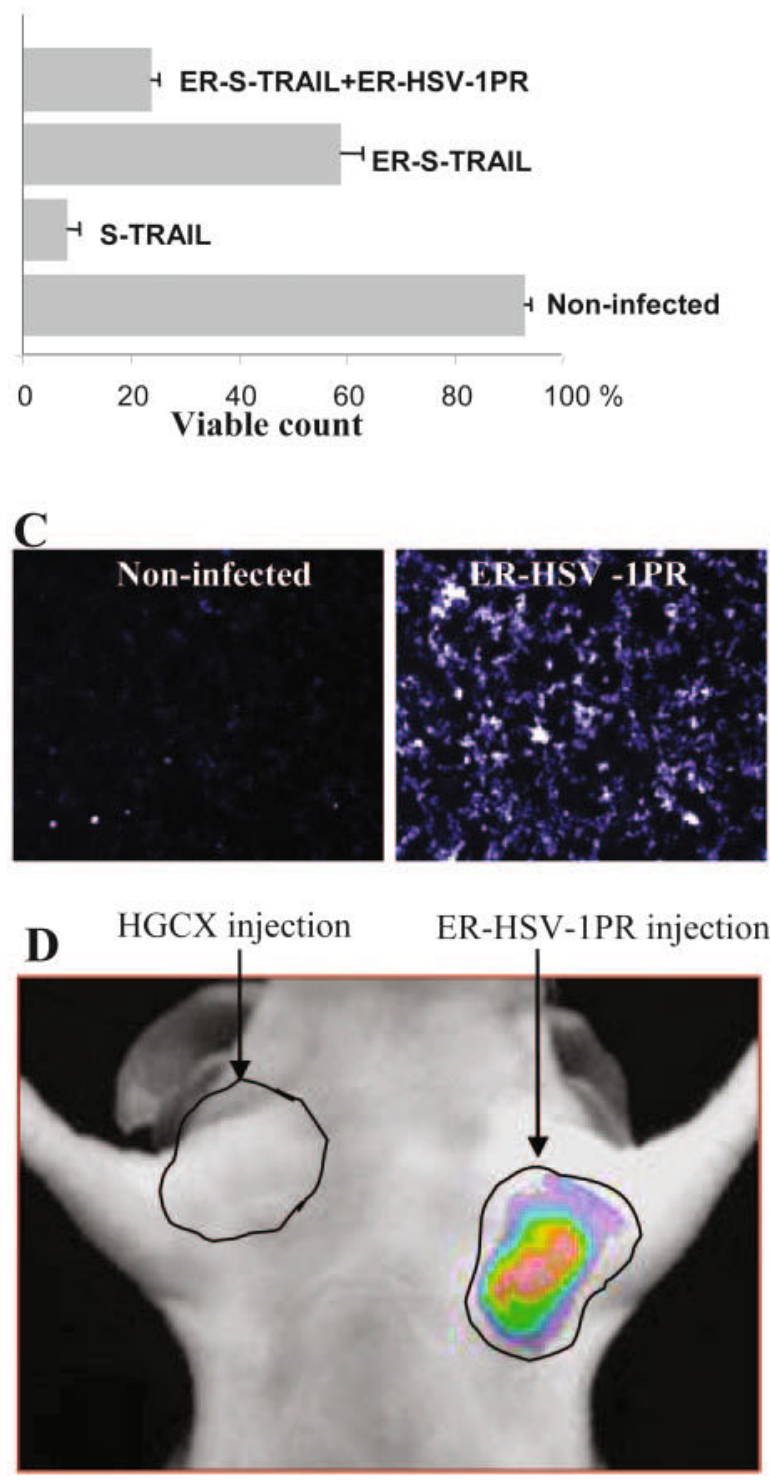

A

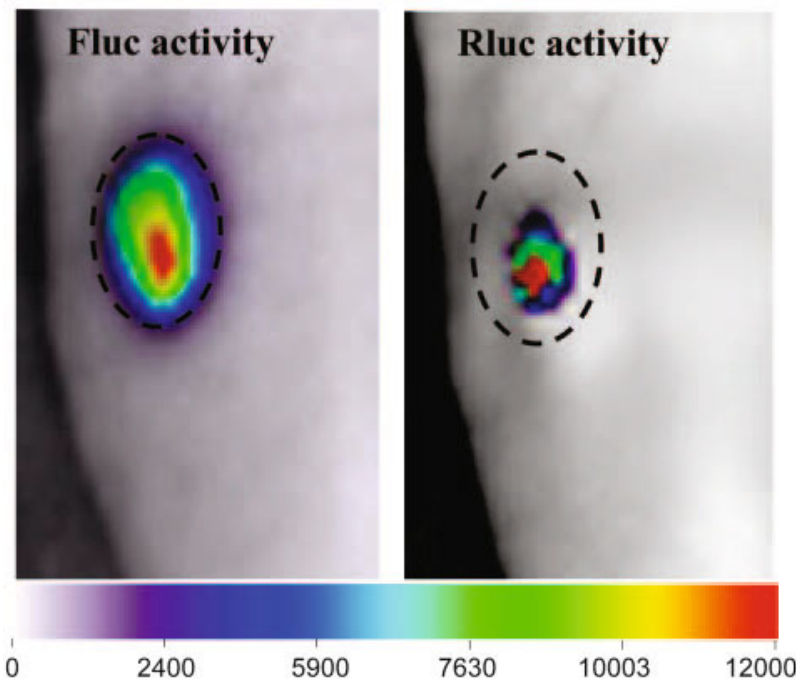

FIG. 4. Dual imaging of amplicon vector delivery and glioma volumes. A: Mice bearing subcutaneous $\mathrm{Gli} 6 \mathrm{fluc}^{+}$gliomas (Gli36 glioma cells stably expressing Fluc were injected intraperitoneally with D-luciferin and imaged for Fluc activity. B: Twenty microliters of A-Rluc amplicon vector $\left(2 \times 10^{5}\right.$ tu total $)$ were injected into the same tumor and $36 \mathrm{~h}$ later, coelenterazine was injected into the tail vein and the mice were imaged for Rluc activity. Each image in A and B represents a scan time of $1 \mathrm{~min}$. The dashed circle around the tumor indicates the tumor periphery. Adapted with permission from Shah et al. Real-time imaging of TRAIL-induced apoptosis of glioma tumors in vivo. Oncogene 22:6865-6872. Copyright (C 2003, Nature Publishing Group. All rights reserved. ${ }^{41}$

efficacy of the therapy. Suicide gene therapy employing the prodrug activating system HSV-1 thymidine kinase (HSV-TK)/ganciclovir (GCV) has proven to be effective in killing experimental brain tumors. In a very recent study, HSV-TK gene was fused to the Fluc gene and the subcutaneous U87MG human malignant glioma cells stably expressing HSV-TK-Luc were subjected to GCV treatment and tumor response to therapy was monitored in vivo by serial bioluminescence imaging. ${ }^{45}$ Serial Fluc imaging of tumor bearing mice detected the GCV-induced death of tumor cells expressing the fusion protein

FIG. 3. Regulation of apoptosis and in vivo imaging of HSV-1PR activity. Gli36 glioma cells were left uninfected or infected with S-TRAIL, ER-S-TRAIL or coinfected with ER-S-TRAIL and ERHSVPR amplicon vectors and $24 \mathrm{~h}$ later cell viability was assessed: (A) microscopically and (B) by water-soluble tetrazolium salt (WST) assays. C: Cultured Gli36 cells were infected with ER targeted HSV-1PR amplicon vectors and $36 \mathrm{~h}$ later cells were exposed to the HSV-1PR-NIRF probe and visualized for NIR fluorescence with a fluorescence microscope $(\times 20$ magnification). D: Mice were implanted with Gli36 glioma cells on both sides in the upper, lateral abdomen, and 7 days later tumors were injected with $20 \mu \mathrm{l}$ of $3.5 \times 10^{8}$ transducing units $(\mathrm{tu}) / \mathrm{ml}$ of ER-HSV-1PR amplicon vector or control vector; $36 \mathrm{~h}$ later mice were administered intravenously with $2.5 \mathrm{nmol}$ of HSV-1PRNIRF probe and imaged $24 \mathrm{~h}$ later using a CCD camera. Adapted with permission from Shah et al. Inducible release of TRAIL fusion proteins from a proapoptotic form for tumor therapy. Cancer Res 64:3236-3242. Copyright (C) 2004, American Association of Cancer Research. All rights reserved. ${ }^{31}$ 

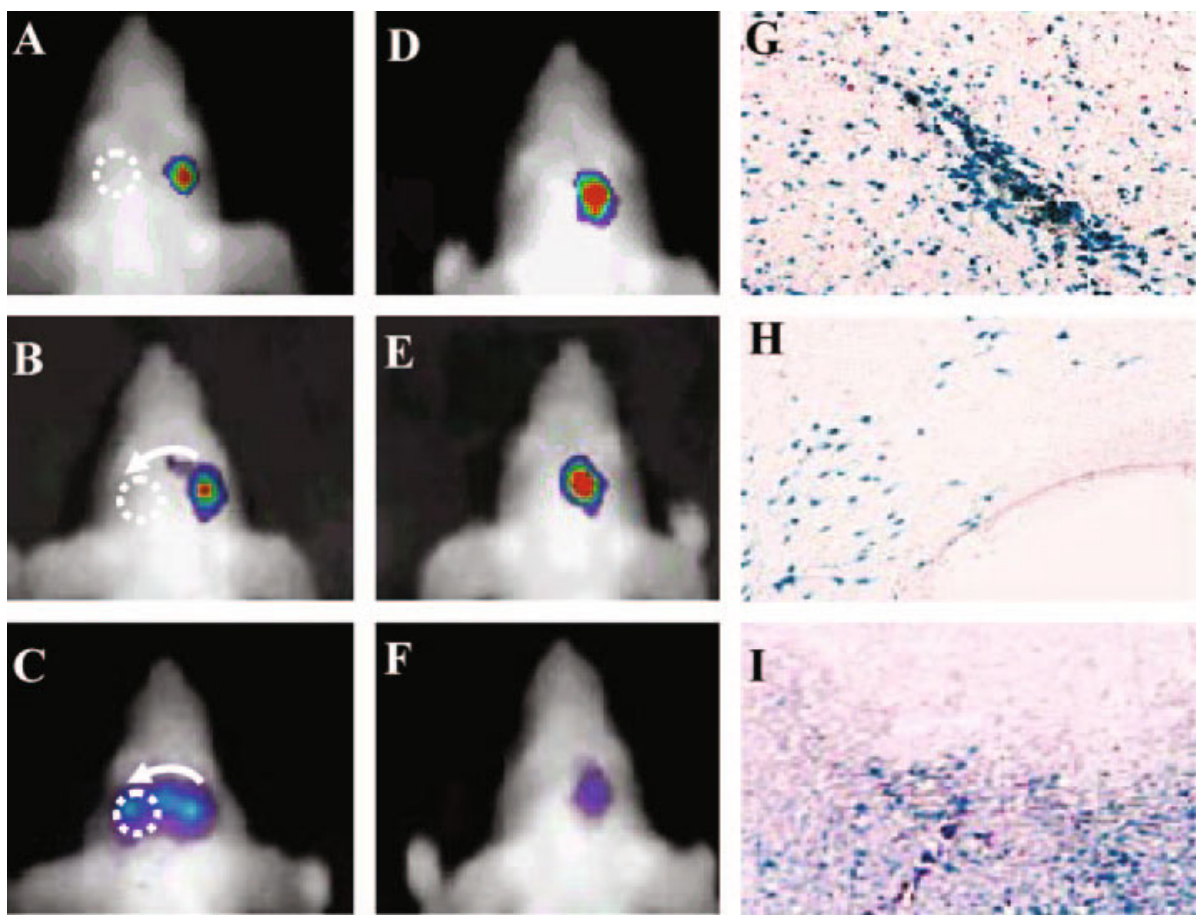

FIG. 5. Parenchymal migration of NPC-LUCs expressing firefly luciferase. NPC-LUC cells (NPCs stably expressing firefly luciferase) were implanted into the right hemisphere of either mice bearing Gli36 tumors in the left hemisphere (A-C) or control mice that did not have tumors (D-F). A-C represent a time series of the same animal from the first group imaged at day 0 (A), 1 week (B) and 2 weeks (C). Migration toward the tumor (dotted circle) was first noted after 1 week (B; see faint bioluminescence signal along arrow) and migration across the midline was evident at 2 weeks. D-F: Time series of another animal representative of the non-tumor-bearing group, in which no migration toward the contralateral side was observed. X-galactosidase staining of coronal sections shows the $\beta$-galactosidase-expressing cells in the injection site $(\mathrm{G})$, the corpus callosum $(\mathrm{H})$, inside the tumor $(\mathrm{I})$. Adapted with permission from Tang et al. In vivo tracking of neuronal progenitor cell migration to glioblastomas. Hum Gene Ther 14:1247-1254. Copyright (C) 2003, Mary Ann Liebert Publishers. All rights reserved. ${ }^{52}$

and proved that bioluminescence can be reliably used for repetitive and noninvasive quantification of HSV-TK/ GCV mediated cell kill in vivo. This approach may represent a valuable tool for the in vivo evaluation of gene therapy strategies for treatment of malignant disease.

\section{DUAL BIOLUMINESCENCE IMAGING}

The ability to image two or more biological processes in a single animal can greatly increase the utility of luciferase imaging by offering the opportunity to distinguish the expression of two reporters biochemically. The luciferases from Renilla and firefly have different substrates, coelenterazine and D-luciferin, respectively, and can be imaged in tumors in the same living mouse with kinetics of light production being separable in time by separate injections of these two substrates. ${ }^{46}$ Dual bioluminescence imaging has been used to monitor gene delivery via a therapeutic vector and to follow the effects of the therapeutic protein TRAIL in gliomas. ${ }^{41}$ Glioma cells stably expressing Fluc were implanted subcutaneously into nude mice, and the tumor growth was monitored in vivo over time by luciferin administration and BLI. HSV amplicon vectors bearing the genes for TRAIL and Rluc were injected directly into these Fluc-positive gliomas allowing super imposition of gene delivery to the tumor by coelentrazine administration and BLI (FIG. 4). This dual imaging approach has direct applications in studying the delivery of gene therapy vectors and simultaneously monitoring therapeutic effects in vivo.

\section{ACTIVATABLE LUCIFERASE}

Recently, activatable luciferase molecules, wherein the luciferase activity has been silenced by fusion with other proteins, have been developed for imaging apoptosis. ${ }^{47}$ Luciferase sequences were flanked at both termini with in-frame caspase-3 substrate sequences and estrogen receptor regulatory domains. Studies in culture with glioma cells expressing this fusion protein revealed attenuated luciferase activity that could be activated on induction of caspase-3. Furthermore, luciferase activation could be monitored in vivo when tumors generated from these cells were treated with TRAIL and underwent apoptosis. ${ }^{47}$ This ability to image caspase- 3 activity noninvasively in vivo provides a unique tool for the evaluation of therapeutic efficacy of experimental therapeutic agents, as well as for studies on the role of apoptosis in development and various disease processes. 


\section{Glioma volumes NPC distribution}
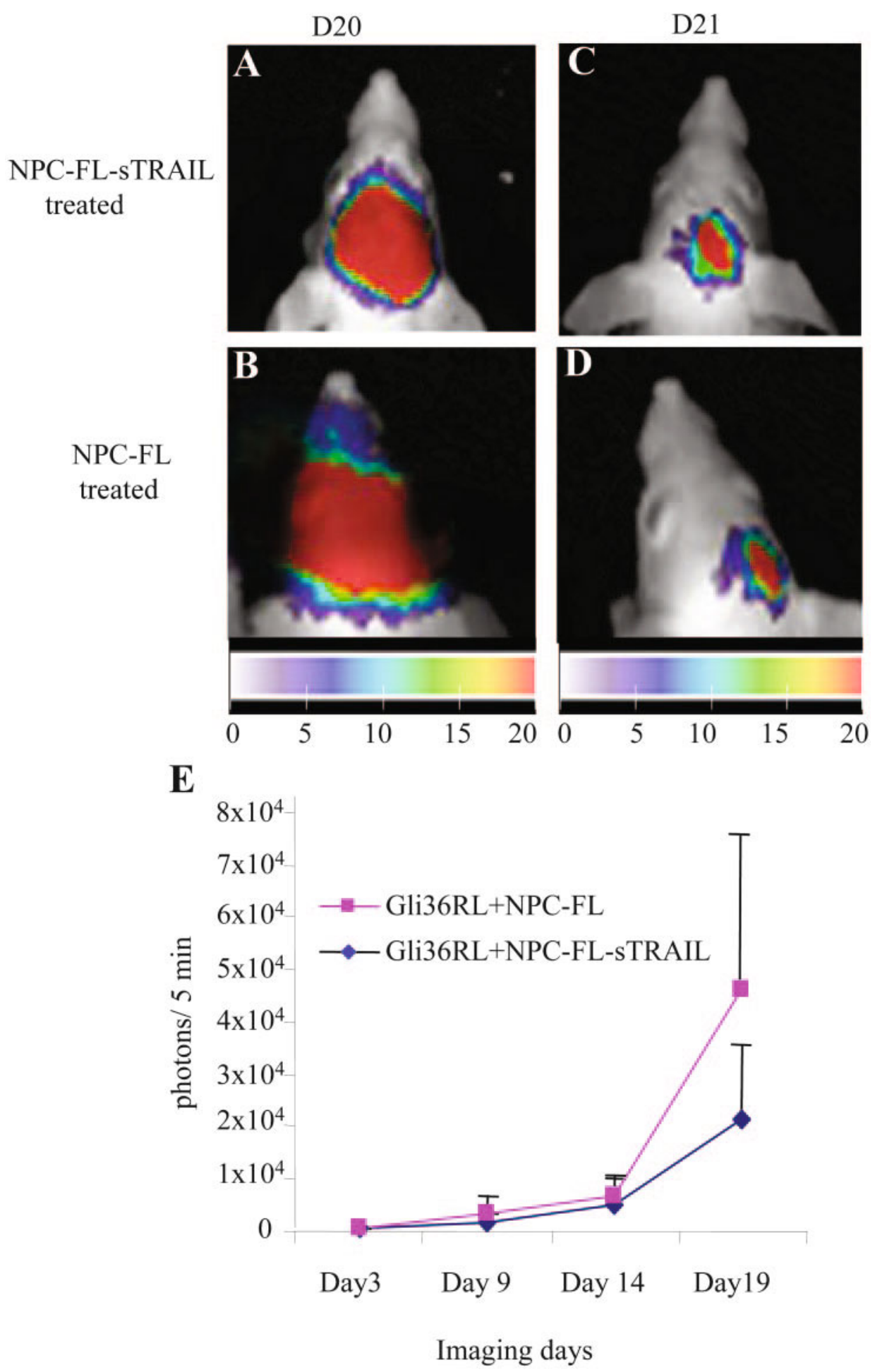

FIG. 6. Dual imaging NPC migration and glioma burden and the effect of STRAIL expressing NPCs on glioma burden. Gli36 glioma cells stably expressing Rluc (Gli36-RL) were implanted into the right frontal lobe and NPC-FLs or NPC-FL-sTRAlLs (NPCs stably expressing Fluc and S-TRAIL) were implanted into the close vicinity of mice bearing an established Gli36-RL glioma. Mice were followed for tumor progression by Rluc imaging and the images of mice injected with NPC-FL-sTRAILs (A) or NPC-FLs (B) after 20 days are shown. The presence of NPC-FL-sTRAILs (C) and NPC-FLs (D) in the tumor was followed by Fluc imaging on day 21. Color coded maps of the photon intensities from Gli36-RL or NSC-FL-sTRAIL and NSC-FL cells are shown. E: Rluc bioluminescence intensities of Gli36-RL tumors in mice implanted with either NPC-FL-sTRAILs or NPC-FLs over time. Adapted with permission from Shah et al. Glioma therapy using TRAIL-sercreting NPCs with dual imaging of NPC migration and tumor regression in vivo. Ann Neurol 57:34-41. Copyright $@$ 2005, John Wiley Co. All rights reserved. ${ }^{54}$ 


\section{NEURAL PRECURSOR CELL TRACKING}

The recognition that neural precursor cells (NPCs) can migrate and integrate appropriately throughout the mammalian CNS following transplantation ${ }^{48,49}$ has unveiled new roles for neural transplantation and gene therapy, and a new strategy for addressing CNS tumors. NPCs can become normal constituents of the host cytoarchitecture and are capable of disseminating bioactive molecules and virus vectors. ${ }^{50,51}$ The ability to noninvasively track the engraftment, migration and proliferation of NPCs has significant clinical and research implications. Recently, we have explored the macroscopic migratory capabilities of NPCs toward experimental tumors after implantation into nude mice at distant sites in the brain. ${ }^{52}$ A line of NPCs stably expressing Fluc was either implanted into the brain parenchyma or administered via intraparenchymal and intraventricular injections into mice bearing intracranial gliomas. Using serial BLI, migration of NPCs implanted in the brain was observed across the corpus callosum toward the tumor, with movement first being detected at 1 week and maximal density within the tumor site observed at 2-3 weeks after implantation (FIG. 5). This is in line with the histologically documented migratory capability of NPCs over considerable distances and their preferential accumulation in brain tumors upon CNS injection. These studies are relevant for potential clinical use because the administration of such cells could carry therapeutically active transgenes and their migratory capability can now be quantitated.

\section{TRACKING THERAPEUTIC EFFICACY AND NEURAL PRECURSOR CELL MIGRATION SIMULTANEOUSLY}

Glioblastomas are the most common primary malignant brain tumors. Over the past 20 years, the incidence of gliomas has increased considerably and the median survival for patients with glioblastomas is less than 2 years ${ }^{53}$ As surgical resection is almost always followed by regrowth of tumor cells residing in adjacent regions of normal brain, new therapies are needed that specifically target tumor cells, especially those cells that have escaped the main tumor mass. In a recent study, we have engineered a secretable form of TRAIL (S-TRAIL) and shown that it has an enhanced apoptosis-inducing and bystander effect for tumor cells. ${ }^{31}$ To extend the release time of S-TRAIL and deliver it directly to invasive tumor cells, we engineered NPCs expressing S-TRAIL and used them as a delivery modality for brain tumor therapy. To track the growth of highly malignant gliomas and migration of NPCs, cell lines were also engineered with luminescent and fluorescent transgenes for fluorescence and dual bioluminescence imaging. ${ }^{54}$ Using a highly ma- lignant human-glioma model expressing Renilla luciferase (RL), intracranially implanted NPCs expressing both Fluc and S-TRAIL were shown to migrate into the tumors and have antitumor effects (FIG. 6). These studies demonstrate the potential of NPCs as therapeutically effective delivery vehicles for the treatment of gliomas and also provide important tools to evaluate the migration of NPCs and changes in glioma-burden in vivo.

\section{CONCLUSIONS}

Noninvasive monitoring of both endogenous and delivered gene expression offers numerous experimental venues for research in animal models. With the development of new optical imaging technologies, investigators in the neurotherapeutic arena are poised to apply and extend current capabilities to assay the progression of diseases and the response to a variety of therapies. It is expected that clinical translation of optical molecular imaging technology will ultimately aid the diagnosis and the development of safe and efficient use of therapeutics. Such advances will likely complement the ongoing developments in radionuclide imaging, ${ }^{55,56} \mathrm{MR}$ imaging, ${ }^{57}$ and MR spectroscopy ${ }^{58}$ in the study of neurotherapeutics.

\section{REFERENCES}

1. Brown EB, Campbell RB, Tsuzuki Y, Xu L, Carmeliet P, Fukumura D, Jain RK. In vivo measurement of gene expression, angiogenesis and physiological function in tumors using multiphoton laser scanning microscopy. Nat Med 7:864-868, 2001.

2. Becker A, Hessenius C, Licha K, Ebert B, Sukowski U, Semmler W, Wiedenmann B, Grotzinger C. Receptor-targeted optical imaging of tumors with near-infrared fluorescent ligands. Nat Biotechnol 19:327-331, 2001.

3. Callahan R, Bogdanov A, Fischman A, Brady T, Weissleder R. Preclinical evaluation and phase 1 clinical trial of a $99 \mathrm{mTc}$ labeled synthetic polymer used in blood pool imaging. Am J Roentgenol 171:137-143, 1998.

4. Tung C, Bredown S, Mahmood U, Weissleder R. Preparation of a cathepsin D sensitive near-infrared fluorescence probe for imaging. Bioconjugate Chem 10:892-896, 1999.

5. Weissleder R, Mahmood U. Molecular imaging. Radiology 219: 316-333, 2001.

6. Yu AE, Hewitt RE, Connor EW. Novel targets for directed cancer therapy. Drugs Aging 11:229-244, 1997.

7. Weissleder R, Tung C-H, Mahmood U, Bogdanov A Jr. In vivo imaging of tumors with protease-activated near-infrared fluorescent probes. Nat Biotech 17:375-378, 1999.

8. Tung $\mathrm{CH}$, Mahmood $\mathrm{U}$, Bredow $\mathrm{S}$, Weissleder R. In vivo imaging of proteolytic enzyme activity using a novel molecular reporter. Cancer Res 60:4953-4958, 2000.

9. Davies, B, Waxman J, Wasan H, Abel P, Williams G, Krausz T, Neal D, Thomas D, Hanby A, Balkwill F. Levels of matrix metalloproteases in bladder cancer correlate with tumor grade and invasion. Cancer Res 53:5365-5369, 1993.

10. Zucker S, Mirza H, Conner CE, Lorenz AF, Drews MH, Bahou WF, Jesty J. Measurement of matrix metalloproteinases and tissue inhibitors of metalloproteinases in blood and tissues. Clinical and experimental applications. Ann NY Acad Sci 878:212-227, 1999. 
11. Black RA, Rauch CT, Kozlosky CJ, Peschon JJ, Slack JL, Wolfson MF, Castner BJ, Stocking KL, Reddy P, Srinivasan S. A metalloproteinase disintegrin that releases tumour-necrosis factor- $\alpha$ from cells. Nature 385:729, 1997.

12. Stearns ME, Wang M. Type IV collagenase (M(r) 72,000) expression in human prostate: benign and malignant tissue. Cancer Res 53:878-883, 1993 .

13. Moses MA, Wiederschain D, Loughlin, KR, Zurakowski D, Lamb $\mathrm{CC}$, Freeman MR. Increased incidence of matrix metalloproteinases in urine of cancer patients. Cancer Res 58:1395-1399, 1998.

14. Shalinsky DR, Brekken J, Zou H, McDermott CD, Forsyth P, Edwards D, Margosiak S, Bender S, Truitt G, Wood A, Varki NM, Appelt K. Broad antitumor and antiangiogenic activities of AG3340, a potent and selective MMP inhibitor undergoing advanced oncology clinical trials. Ann NY Acad Sci 878:236-270, 1999.

15. Rooprai HK, McCormick D. Proteases and their inhibitors in human brain tumours: a review. Anticancer Res 17:4151-4162, 1997.

16. Bremer $\mathrm{C}$, Tung $\mathrm{CH}$, Weissleder $\mathrm{R}$. In vivo molecular target assessment of matrix metalloproteinase inhibition. Nat Med 7:743748, 2001.

17. Gondi CS, Lakka SS, Yanamandra N, Siddique K, Dinh DH, Olivero WC, Gujrati M, Rao JS. Expression of antisense uPAR and antisense uPA from a bicistronic adenoviral construct inhibits glioma cell invasion, tumor growth, and angiogenesis. Oncogene 22:5967-5975, 2003.

18. Gondi CS, Lakka SS, Yanamandra N, Olivero WC, Dinh DH, Gujrati M, Tung CH, Weissleder R, Rao JS. Adenovirus mediated expression of antisense urokinase plasminogen activator receptor and antisense cathepsin B inhibits tumor growth, invasion and angiogenesis in gliomas. Cancer Res 64:4069-4077, 2004.

19. Reed JC. Apoptosis-based therapies. Nat Rev Drug Disc 1:111121, 2002.

20. Thornberry N, Lazebnik Y. Caspases: enemies within. Science 281:1312-1316, 1998.

21. Bustamante J, Bersier G, Romero M, Badin RA, Boveris A. Nitric oxide production and mitochondrial dysfunction during rat thymocyte apoptosis. Arch Biochem Biophys 376:239-247, 2000.

22. Kim YM, Chung HT, Simmons RL, Billiar TR. Cellular non-heme iron content is a determinant of nitric oxide-mediated apoptosis, necrosis, and caspase inhibition. J Biol Chem 275:10954-10961, 2000.

23. Thornberry NA, Bull HG, Calaycay JR, Chapman KT, Howard AD, Kostura MJ, Miller, DK, Molineaux, SM, Weidner JR, Aunins $\mathrm{J}$. A novel heterodimeric cysteine protease is required for interleukin-1 $\beta$ processing in monocytes. Nature 356:768-774, 1992.

24. Messerli S, Prabhakar S, Tang Y, Shah K, Cortes M, Murthy V, Weissleder R, Breakefield XO, Tung, CH. A novel method for imaging apoptosis using a caspase-1 (ICE) near-infrared imaging probe. Neoplasia 6:95-105, 2004.

25. Schlegel RA, Williamson P. Phosphatidylserine, a death knell. Cell Death Differ 8:551-563, 2001.

26. Schellenberger EA, Bogdanov A Jr, Petrovsky A, Ntziachristos V, Weissleder R, Josephson L. Optical imaging of apoptosis as a biomarker of tumor response to chemotherapy. Neoplasia 5:187$192,2003$.

27. Shah $\mathrm{K}$, Tung $\mathrm{CH}$, Chang J, Weissleder R, Breakefield XO. In vivo imaging of HIV-1 protease activity in amplicon vector transduced gliomas. Cancer Res 64:273-278, 2004.

28. Wiley SR, Schooley K, Smolak PJ, Din WS, Huang CP, Nicholl JK, Sutherland GR, Smith TD, Rauch C, Smith CA. Identification and characterization of a new member of the TNF family that induces apoptosis. Immunity 3:673-682, 1995.

29. Pan G, Ni J, Wei YF, Yu G, Gentz R, Dixit VM. An antagonist decoy receptor and a death domain-containing receptor for TRAIL. Science 277:815-818, 1997.

30. Ashkenazi A, Dixit VM. Apoptosis control by death and decoy receptors. Curr Opin Cell Biol 11:255-260, 1999.

31. Shah K, Tung CH, Yang K, Weissleder R, Breakefield XO. Inducible release of TRAIL fusion proteins from a proapoptotic form for tumor therapy. Cancer Res 64:3236-3242, 2004.

32. Muszbek L, Yee VC, Hevessy Z. Blood coagulation factor XIII: structure and function. Thromb Res 94:271-305, 1999.
33. Jaffer FA, Tung CH, Wykzykowska JJ, Ho NH, Houng AK, Reed GL, Weissleder R. Molecular imaging of factor XIIIa activity in thrombosis using a novel, NIRF contrast agent that covalently links to thrombi. Circulation 110:170-176, 2004.

34. Contag CH, Ross BD. It's not just about anatomy: in vivo bioluminescence imaging as an eyepiece into biology. J Magn Reson Imaging 16:378-387, 2002.

35. Rice BW, Cable MD, Nelson MB. In vivo imaging of light-emitting probes. J Biomed Opt 6:432-440, 2001.

36. Honigman A, Zeira E, Ohana P, Abramovitz R, Tavor E, Bar I, Zilberman Y, Rabinovsky R, Gazit D, Joseph A, Panet A, Shai E, Palmon A, Laster M, Galun E. Imaging transgene expression in live animals. Mol Ther 4:239-249, 2001.

37. Contag CH, Jenkins D, Contag PR, Negrin RS. Use of reporter genes for optical measurements of neoplastic disease in vivo. Neoplasia 2:41-52, 2000.

38. Wu JC, Sundaresan G, Iyer M, Gambhir SS. Noninvasive optical imaging of firefly luciferase reporter gene expression in skeletal muscles of living mice. Mol Ther 4:297-306, 2001.

39. Sweeney TJ, Mailander V, Tucker AA, Olomu AB, Zhang W, Cao Y, Negrin RS, Contag CH. Visualizing the kinetics of tumor-cell clearance in living animals. Proc Natl Acad Sci USA 96:1204412049, 1999.

40. Contag CH, Contag PR, Mullins JI, Spilman SD, Stevenson DK, Benaron DA. Photonic detection of bacterial pathogens in living hosts. Mol Microbiol 18:593-603, 1995.

41. Shah K, Tang Y, Breakefield XO, Weissleder R. Real-time imaging of TRAIL-induced apoptosis of glioma tumors in vivo. Oncogene 22:6865-6872, 2003.

42. Ntziachristos V, Kreis R, Boesch C, Quistorff B. Diploar resonance frequency shifts in 1H MR spectra of skeletal muscle: confirmation in rats at $4.7 \mathrm{~T}$ in vivo and observation of changes postmortem. Magn Reson Med 38:33-39, 1997.

43. Shah K, Jacobs A, Breakefield XO, Weissleder R. Molecular imaging of gene therapy for cancer. Gene Ther 11:1175-1187, 2004.

44. Rehemtulla A, Hall DE, Stegman LD, Prasad U, Chen G, Bhojani MS, Chenevert TL, Ross BD. Molecular imaging of gene expression and efficacy following adenoviral-mediated brain tumor gene therapy. Mol Imaging 1:43-55, 2002.

45. Soling A, Theiss C, Jungmichel S, Rainov NG. A dual function protein of HSV-1 TK and Fluc for non invasive in vivo imaging of gene therapy in malignant gliomas. Genet Vaccines Ther 2:7, 2004.

46. Bhaumik S, Gambhir SS. Optical imaging of Renilla luciferase reporter gene expression in living mice. Proc Natl Acad Sci USA 99:377-382, 2002.

47. Laxman B, Hall DE, Bhojani MS, Hamstra DA, Chenevert TL, Ross BD, Rehemtulla A. Noninvasive real-time imaging of apoptosis. Proc Natl Acad Sci USA 99:16551-16555, 2002.

48. Aboody KS, Brown A, Rainov NG, Bower KA, Liu S, Yang W, Small JE, Herrlinger U, Ourednik V, Black PM, Breakefield X, Snyder EY. Neural stem cells display extensive tropism for pathology in adult brain: evidence from intracranial gliomas. Proc Natl Acad Sci USA 97:12846-12851, 2000.

49. Ourednik J, Ourednik V, Lynch WP, Schachner M, Snyder EY. Neural stem cells display an inherent mechanism for rescuing dysfunctional neurons. Nat Biotechnol 20:1103-1110, 2002.

50. Snyder EY, Deitcher DL, Walsh C, Arnold-Aldea S, Hartwieg EA, Cepko CL. Multipotent neural cell lines can engraft and participate in development of mouse cerebellum. Cell 68:33-51, 1992.

51. Herrlinger U, Woiciechowski C, Sena-Esteves M, Aboody KS, Jacobs AH, Rainov NG, Snyder EY Breakefield XO. Neural precursor cells for delivery of replication-conditional HSV-1 vectors to intracerebral gliomas. Mol Ther 1:347-357, 2000.

52. Tang Y, Shah K, Messerli SM, Snyder E, Breakefield XO, Weissleder R. In vivo tracking of neuronal progenitor cell migration to glioblastomas. Hum Gene Ther 14:1247-1254, 2003.

53. Stiles CD. Cancer of the central nervous system. Review of an AACR special conference in cancer research with the joint section on tumors of the AANS/CNS (San Diego, CA, June 7-11, 1997). Biochim Biophys Acta 1377:R1-R10, 1998.

54. Shah K, Bureau E, Kim D, Yang K, Tang Y, Weissleder R, Breakefield XO. Glioma therapy using TRAIL-secreting NPCs 
with dual imaging of NPC migration and tumor regression in vivo. Ann Neurol 57:34-41, 2005.

55. Brooks DJ. Positron emission tomography and single-photon emission computed tomography in central nervous system drug development. NeuroRx 2:226-236, 2005.

56. Devous MD. Single-photon emission computed tomography in neurotherapeutics. NeuroRx 2:237-239, 2005.
57. Bammer R, Skare S, Newbould R, Liu C, Thijs V, Ropele S, Clayton DB, Krueger G, Moseley ME, Glover GH. Foundations of advanced magnetic resonance imaging. NeuroRx 2:167-196, 2005.

58. Lin A, Ross, BD, Harris K, Wong W. Efficacy of proton magnetic resonance spectroscopy in neurological diagnosis and neurotherapeutic decision-making. NeuroRx 2:197-214, 2005. 